\title{
Effectiveness of Hand Hygiene Video cum Demonstration on Knowledge and Practice, among Mothers of Neonates Admitted in NICU
}

\author{
Sangithaa Varsha G. ${ }^{1}$, Geetha D. ${ }^{2}$, Anita David ${ }^{3}$ \\ 1,2,3 Department of Child Health Nursing, Sri Ramachandra Institute of \\ Higher Education and Research, Porur, Chennai, Tamil Nadu, India.
}

\section{ABSTRACT}

\section{BACKGROUND}

Proper hand hygiene is the single most important, simplest, and least expensive means of reducing the prevalence of health care association infection (HAIs) and nosocomial infection. Several studies have demonstrated that hand washing virtually eradicates the carriage of infections in intensive care units (ICUs). For more than 150 years, hand hygiene has been researched in the hospital environment as a way of preventing transmission of bacteria, infection and death. The purpose of this study was to import the significance of the hand hygiene and to improve the skills in performing hand hygiene among mothers of neonates admitted in neonatal intensive care unit (NICU) at tertiary care hospital.

\section{METHODS}

A self structured knowledge questionnaire (KQ), practice questionnaire (PQ) and practice checklist (PC) was administered. The one to one method video on hand hygiene was played by using a laptop for about 15 minutes as an intervention with demonstration done by investigator and return demonstration was done by mothers, post test was conducted on $3^{\text {rd }}$ day and $5^{\text {th }}$ day followed by the intervention.

\section{RESULTS}

The mean scores of knowledge showed improvement in post test than the pre test in both the groups, but there was an increase in practice mean score between the groups which showed an improvement in the study group, it was higher than the control group which was statistically significant at $\mathrm{P}<0.001$. Overall, there were minimal positive correlations between the level of knowledge and practice for the study group in post-test and post-test II. Minimum positive correlation was evident but there was no significance.

\section{CONCLUSIONS}

This study concludes that it enhanced the knowledge on hand hygiene among mothers of neonates and it helped mothers to understand the importance of hand hygiene, when to do, how to do, why to do. Thus, it expected directly or indirectly to reduce the infection rate among neonates admitted in NICU. Further, the nurses have a great responsibility in ensuring parents adherence to hand hygiene.

\section{KEY WORDS}

Mothers of Neonate in NICU, Hand Hygiene, Video cum Demonstration, Mothers KPC.
Corresponding Author:

Dr. Geetha $D$,

Lecturer,

Department of Child Health Nursing,

Faculty of Nursing, Sri Ramachandra Institute of Higher Education and

Research, Porur, Chennai - 600116,

Tamil Nadu, India.

E-mail: geetha.d@sriramachandra.edu.in

DOI: $10.14260 / \mathrm{jemds} / 2021 / 571$

How to Cite This Article:

$G$ Sangithaa V, D Geetha, David A. Effectiveness of hand hygiene video cum demonstration on knowledge and practice, among mothers of neonate admitted in nicu. J Evolution Med Dent Sci 2021;10(33):2799-2802, DOI: $10.14260 / \mathrm{jemds} / 2021 / 571$

Submission 07-12-2020,

Peer Review 12-07-2021,

Acceptance 18-07-2021,

Published 16-08-2021.

Copyright (c) 2021 Sangithaa Varsha G. et al. This is an open access article distributed under Creative Commons Attribution License [Attribution 4.0 International (CC BY 4.0)] 


\section{BACKGROUND}

Arrival of a newborn creates a lot of changes in the family. At the same time poor immune power and organ immaturity easily affects them to get infection within a short period of time. Globally, 4 million new born die every year before they reach the age of one month. Out of them, 1.5 million new borns die in four countries of South Asia (WHO 2006). In India, 26 million babies are born every year, and 1.2 million die in the first four weeks of life, which accounts for a quarter of global neonatal deaths. India thus faces the biggest newborn health challenge of any country in the world. ${ }^{1}$

In the NICU, newborns may be a source of infection for other infants or newborns and themselves. ${ }^{2}$ The most common nosocomial infections of newborns include blood infection, pneumonia, urinary tract infection, surgical wound infection, ear, throat, nose and eye infections, gastrointestinal tract infections, skin and soft tissue infections. ${ }^{3}$ Diarrhoea is one of the leading causes of death among newborns, infants and children globally. Diarrhoea is responsible for the death of 1 in 9 child's death worldwide. More than 0.7 million under five children are dying every year due to diarrhoea in the world. In India the death rate is seen higher among lakhs of children because of diarrhea". ${ }^{4}$

Almost 1,400,000 people suffer from complications of nosocomial infection throughout the world. In developing countries, preventable $\mathrm{HAI}$ is estimated to be $40 \%$ and higher. ${ }^{3}$ It is also one of the most important problems in intensive care units. NICU is sensitive to nosocomial infections which are often difficult to control." Neonates are prone for infection as their immune system is not developed. They are part of the environment in which frequently used antibiotics and invasive interventions often permit the invasion of common nosocomial pathogens and the close proximity of patients in many NICUs facilitates transfer of organisms from one neonate to another neonate. In a crosssectional study done to assess the knowledge and practice of hand washing among health professionals in Dubti referral hospital stated that out of 91 respondents $65.9 \%$ (50) of them were knowledgeable and $34.1 \%$ (41) of hand washing among health care professionals. ${ }^{5}$

The knowledge and practice regarding hand washing in the community is poor even today. Hand washing if regularly and properly practiced by mothers of neonates, will reduce the prevalence of infectious diseases. ${ }^{6}$ In the appropriate method of hand washing technique, when to wash, how to wash, most of the mothers were having doubts and were not able to follow it correctly when handling the newborns. So newborn mortality and morbidity rate was increased because of poor hand washing practice followed by mother's health care works and family members. If hand hygiene is regularly and properly practiced by mothers of neonates, it will go a long way in reducing the prevalence of infectious disease. Practicing hand hygiene becomes an important responsibility of a mother attending newborns admitted in the NICU. With this concern, the investigator has taken a step to import knowledge and practice on hand hygiene among mothers through the video cum demonstration method.

The researcher has taken up the current study to assess the effectiveness of hand hygiene video cum demonstration on knowledge and practice among mothers of neonates admitted in NICU at tertiary care hospitals.

\section{Purpose}

The purpose of this study was to import the significance of the hand hygiene and to improve the skills in performing hand hygiene among mothers of neonates admitted in NICU at tertiary care hospital.

\section{METHODS}

A quasi-experimental research design was adopted for the study. A non-probability convenience sampling technique was used to select the samples during the study period. 60 mothers of neonates fulfilling inclusion were selected. The structured questionnaire constructed by the researcher based on literature review was used to assess the knowledge on hand hygiene among mothers of neonates admitted in NICU. It consists of 15 multiple choice questions with the components on indications for hand washing, preparation for before hand washing, substance used for hand washing, steps in hand washing and benefits of hand hygiene. The total possible score for every correct answer was one and wrong answer was zero. The overall score $<50 \%$ categorized as inadequate knowledge; 51 to $75 \%$ categorized to have moderate knowledge and $>75 \%$ categorized as adequate knowledge. The practice questionnaire was devised by the researcher and it was used to assess the hand hygiene practice of mothers. The total number of items were 10 . The highest possible score was 30 . It was assessed by using a 3 point Likert scale. The other tool developed to assess the steps followed by the mothers during hand hygiene. It consisted of 16 items with YES or NO options.

After obtaining the Institutional Ethics Committee approval, the data collection was started. The data collection was done in Sri Ramachandra Hospital, Porur, and Chennai. The data collection duration was from November 2019 to December 2019. Self-structured knowledge questionnaires $(\mathrm{KQ})$ and practice questionnaire (PQ) were administered during pretest on $1^{\text {st }}$ day by an interview method video played by using laptop for about 15 minutes as an intervention with demonstration done by investigator and return demonstration was done by mothers. Post test I was on $3^{\text {rd }}$ day, self structured practice checklist (PC) was done. Post test II was on $5^{\text {th }}$ day, knowledge questionnaires (KQ), practice questionnaire (PQ) and practice checklist (PC) was done.

\section{RESULTS}

Description of mothers of neonates according to their demographic variables in study and control group describes the frequency and percentage distribution of demographic variables of both the groups. According to the age 12 (40.2\%) samples in the study group and $13(43.5 \%)$ samples in the control group belonged to 22 - 26 years of age. According to parity, $17(56.5 \%)$ in the study group belonged to primi parity and $16(53.5 \%)$ in the control group belongs to multi parity. With respect to type of delivery, 17 (56.5\%) mothers of neonates had normal delivery and equal to 17 (56.5\%) 
mothers of neonates had lower segment caesarean section (LSCS) in the control group. In relation to education, 17 mothers (56.5 \%) in the study group graduated and 18 (60 $\%)$ mothers in the control group had higher secondary education, which was significant at $\mathrm{P}<0.05$. According to occupation, 12 (40\%) mothers in the study group were homemakers and $10(33.5 \%)$ in the control group belonged to government employees. Also this table shows that there was a significant difference between the study and control group of mothers of neonates in terms of educational status of the mother.

\begin{tabular}{|cccccccccc|}
\hline Level of & \multicolumn{4}{c}{ Study Group } & \multicolumn{4}{c|}{ Control Group } \\
Knowledge & Pre Test & Post Test & Pre Test & Post Test \\
Adequate & $\mathrm{f}$ & $\%$ & $\mathrm{f}$ & $\%$ & $\mathrm{f}$ & $\%$ & $\mathrm{f}$ & $\%$ \\
Moderate & 0 & 0 & 27 & 90 & 0 & 0 & 2 & 6.7 \\
Inadequate & 28 & 93.3 & 3 & 10 & 26 & 86.7 & 26 & 86.7 \\
\hline & 6.7 & 0 & 0 & 4 & 13.3 & 2 & 6.7 \\
\hline \\
Table 1. Level of Knowledge among Mothers of \\
Neonates in Study and Control Group (N=60) \\
\hline
\end{tabular}

\begin{tabular}{|c|c|c|c|c|c|c|c|}
\hline \multirow{2}{*}{$\begin{array}{l}\text { Duration } \\
\text { of Study }\end{array}$} & \multicolumn{2}{|c|}{ Study Group } & \multicolumn{2}{|c|}{ Control Group } & \multirow{2}{*}{$\begin{array}{c}\text { Mean } \\
\text { Difference }\end{array}$} & \multirow{2}{*}{ t Value } & \multirow{2}{*}{ P Value } \\
\hline & Mean & SD & Mean & SD & & & \\
\hline Pretest & 4.9 & 1.46 & 4.8 & 1.47 & 0.1 & 0.26 & 0.79 \\
\hline Post test & 14.2 & 1.35 & 5.3 & 1.95 & 8.9 & 20.5 & $0.00^{* * *}$ \\
\hline \multicolumn{8}{|c|}{$\begin{array}{c}\text { Table 2.Comparison of Level of Knowledge among } \\
\text { Mothers of Neonates in Pre-Test, Post-Test and t Value } \\
\text { between the Study and Control Group }\end{array}$} \\
\hline
\end{tabular}

Table I. shows during pretest, 2 (6.7 \%) had inadequate knowledge, 28 (93.3\%) had moderate knowledge and in post test, 27 (90\%) had adequate level of knowledge, 3 (10\%) had moderate level of knowledge in the study group. Among control group, during pre test $0(0 \%)$ had inadequate level of knowledge 26 (86.7 \%) had moderate level of knowledge and in post test $4(13.3 \%)$ had inadequate knowledge. In post test, 26 (86.7 \%) had moderate adequate knowledge, 2 (6.7) had inadequate knowledge, 2(6.7) had adequate knowledge. Table 2. shows that the mean of knowledge in the study group was 4.9 and in the control group it was 4.8 which was not significant at $\mathrm{P}<0.05$ at pre test.

In post test, the mean for the study group was 14.2 and the control group was 5.3. The post test mean scores on knowledge were higher in the study group as compared to the control group. The increase in knowledge was statistically significant for the study group in post test $\mathrm{P}=0.0001$.

\begin{tabular}{|c|cccccccc|}
\hline Level of & \multicolumn{3}{c}{ Study Group } & \multicolumn{3}{c|}{ Control Group } \\
Practice & Pre Test & Post Test & Pre Test & Post Test \\
Adequate & 0 & $\%$ & f & $\%$ & f & $\%$ & f & $\%$ \\
Moderate & 1 & 0 & 27 & 90 & 0 & 0 & 24 & 80 \\
Inadequate & 29 & 96.33 & 3 & 10 & 2 & 6.67 & 6 & 20 \\
\hline \multicolumn{4}{c}{ Table 3. Level of Practice among Mothers } \\
of Neonates in the Study Group and Control Group \\
\hline
\end{tabular}

Table 3. shows that during pretest, 29 (96.67\%) had inadequate practice, 1 (3.3\%) had moderate practice and in posttest, 27 (90\%) had adequate level of practice, $3(10 \%)$ had moderate level of practice in study group. Among control group, during pre test, 28 (93.3\%) had inadequate level of practice, $2(6.7 \%)$ had moderate level of practice and in post test, 24 (80\%) had adequate knowledge, 6 (20\%) had moderate knowledge.

\begin{tabular}{|c|c|c|c|c|c|c|}
\hline $\begin{array}{l}\text { Sl. } \\
\text { No. }\end{array}$ & Study Group & Mean & SD & $\begin{array}{c}\text { Mean } \\
\text { Difference }\end{array}$ & T Value & P Value \\
\hline \multirow{2}{*}{1} & Pretest - $1^{\text {st }}$ day $(P Q)$ & 12.37 & 1.19 & \multirow{2}{*}{11.93} & \multirow{2}{*}{28.0} & \multirow{2}{*}{$0.0001^{* * *}$} \\
\hline & Post test - $5^{\text {th }}$ day (PQ) & 24.3 & 2.0 & & & \\
\hline \multirow{2}{*}{2} & Pretest - $1^{\text {st }}$ day (PQ) & 12.37 & 1.19 & \multirow{2}{*}{-4.94} & \multirow{2}{*}{12.63} & \multirow{2}{*}{$0.0001^{* * *}$} \\
\hline & Post test I - 3rd day(PC) & 7.43 & 1.78 & & & \\
\hline \multirow{2}{*}{3} & Pretest - $1^{\text {st }}$ day (PQ) & 12.37 & 1.19 & \multirow{2}{*}{3.13} & \multirow{2}{*}{12.14} & \multirow{2}{*}{$0.0001^{* * *}$} \\
\hline & Post test II - $5^{\text {th }}$ day(PC) & 15.5 & 0.76 & & & \\
\hline \multirow{2}{*}{4} & Post test I - $3^{\text {rd }}$ day(PC) & 7.43 & 1.78 & \multirow{2}{*}{8.07} & \multirow{2}{*}{22.8} & \multirow{2}{*}{$0.0001^{* * *}$} \\
\hline & Post test II - $5^{\text {th }}$ day (PC) & 15.5 & 0.76 & & & \\
\hline \multicolumn{7}{|c|}{$\begin{array}{l}\text { Table 4. Comparison of Level of Practice among Mothers of } \\
\text { Neonates at Different Periods of Time within the Study Group. }\end{array}$} \\
\hline & 0.001 & & & & & \\
\hline
\end{tabular}

Table 4. shows comparison of level of practice within the study group, it reveals that the mean score in the pretest was $12.37 \pm 1.46$. After the implementation of video cum demonstration, there was a significant improvement in mean scores of practice during posttest which was $24.3 \pm 2.0$ and in post test I, it was $7.43 \pm 1.78$ and in post test II, it was $15.5 \pm$ 0.76 respectively. The level of practice between pretest and post test, post test I and post test II was statistically significant at $\mathrm{P}<0.001$ level.

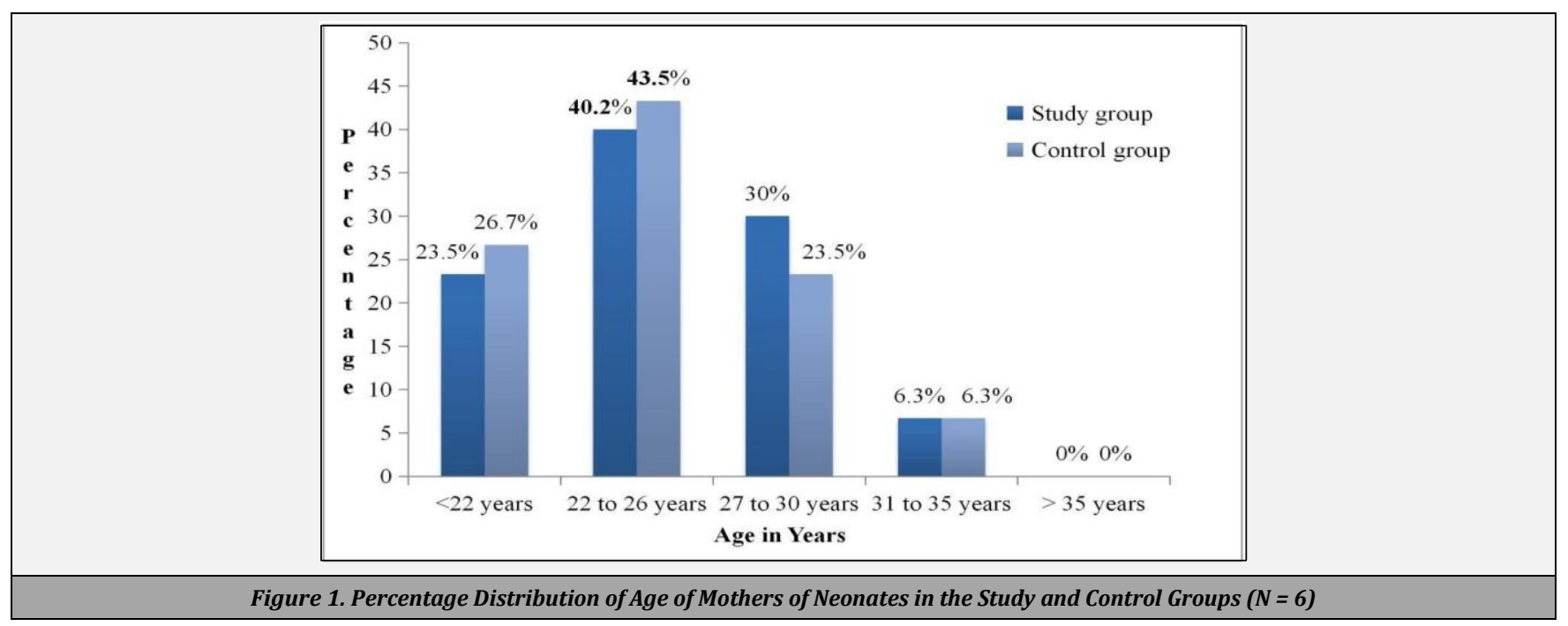

Table 5. shows comparison of level of practice within the control group. It reveals the mean score in the pretest was $12.93 \pm 1.56$ and in the post test it was $13.63 \pm 1.87$, in post test I \& II it was $5.87 \pm 2.48$ and $5.93 \pm 2.32$ respectively. Also the mean score of practice between pre test and post test I 
and between pre test and post test II was statistically significant at $\mathrm{P}<0.001$ level.

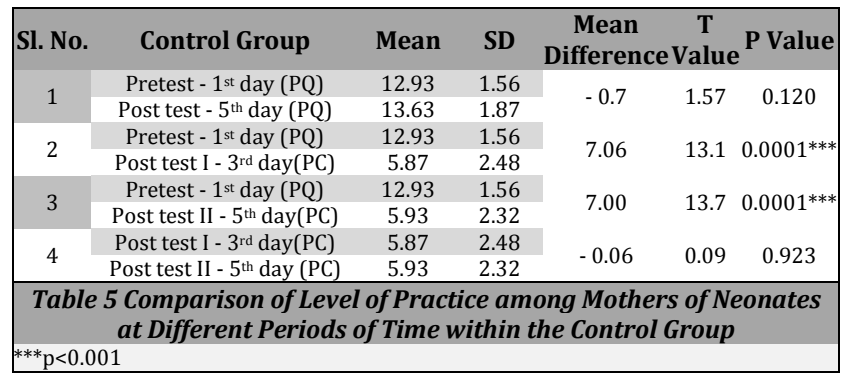

There was no significant correlation between knowledge and practice in pretest and in post test of study group. In control group, no significant correlation between knowledge and practice in pretest and in posttest was found.

\section{DISCUSSION}

The study reveals that post test mean scores on knowledge were higher in the study group when compared to the control group. The increase in knowledge was statistically significant for the study group mothers in post test at $\mathrm{P}<0.05$. This proves that video cum demonstration was effective in improving the knowledge and practices among mothers of neonates.

The result was supported by a similar study conducted by Nice Joseph (2016) to determine the effectiveness of structured teaching programmes on hand hygiene among food handlers. The study results showed that the structured teaching programme was effective in improving the hand hygiene among food handlers with a significant difference between pretest and post test I and II knowledge scores $(\mathrm{t}=$ 32.6 and 28.7, $\mathrm{P}<0.05$ ) and a significant difference was found between pretest and post test I and II practice scores $(\mathrm{t}$ $=9.6$ and 11.1, $\mathrm{P}<0.05)$. Hence the stated hypothesis $\mathrm{H} 1$ Hand hygiene video cum demonstration enhances the knowledge and practice on hand hygiene among mothers of neonates admitted in NICU is accepted. Regarding correlation between knowledge and practice among mothers of neonates in the study and control groups, there was a moderately significant positive correlation that existed between knowledge and practice in pretest $(r=0.077)$ and in post test $(\mathrm{r}=0.044)$ of the study group at $\mathrm{P}<0.05$. This shows when knowledge improves the practice also improves in the study group.

In post test $\mathrm{I}$, there was a negative correlation found between $r=-0.124$ between knowledge and practice for the study group and $r=-0.027$, for the control group. In post test II, there was a moderately positive correlation $r=.112$ that existed between knowledge and practice for the study group and a moderately negative correlation was found $r=-0.164$ in the control group at $\mathrm{P}<0.05$. This shows that there is a minimum positive weak correlation between the level of knowledge and practice for the study group in post test II.

Findings of the study were also supported by Almas, S 2021 on knowledge and practice regarding hand washing among mothers of under five children in selected community area. Results showed that there was no strong correlation between the practice score and knowledge ( $\mathrm{P}$ - value is 0.012 at 0.01 level of significance), but it has shown significant positive weak correlation.

\section{CONCLUSIONS}

The current study enhanced the knowledge on hand hygiene among mothers of neonates and it helped mothers to understand the importance of hand hygiene, when to do, how to do, why to do. Thus, it expected directly or indirectly to reduce the infection rate among neonates admitted in NICU. Further, the nurses have a great responsibility in ensuring the parents adherence of hand hygiene.

\section{Limitations of Our Study}

The sample size of neonatal mothers was 60 and hence generalization is not possible. The data collection period was limited for one month.

Data sharing statement provided by the authors is available with the full text of this article at jemds.com.

Financial or other competing interests: None.

Disclosure forms provided by the authors are available with the full text of this article at jemds.com.

\section{REFERENCES}

[1] Kotwal YS, Yatoo GH, Jan AF. Morbidity and mortality among neonates admitted to a neonatal intensive care unit of a tertiary care teaching hospital of Jammu and Kashmir (India). Neonat Pediatr Med 2017;3(2):136.

[2] Pessoa-Silva CL, Hugonnet S, Pfister R, et al. Reduction of healthcare-associated infection risk in neonates by successful hand hygiene promotion. Pediatrics 2007;120(2):e382-90.

[3] Maher A, Eslami Z, Ali-Mohammadzadeh K. Effect of hand hygiene education on knowledge, attitude and practice of NICU and pediatric staff in Zanjan Hospitals. Int Acad J of Organ Behav and Human Resource Management 2016;3(2):35-43.

[4] Mech K, Ojah J. A study on the awareness and practices of hand washing amongst mothers of under-five children in the slums of Guwahati city. Journal of Evidence Based Medicine and Healthcare 2016;3(24):1075-8.

[5] Jemal S. Knowledge and practices of hand washing among health professionals in Dubti Referral Hospital, Dubti, Afar, Northeast Ethiopia. Advances in Preventive Medicine 2018;2018:5290797.

[6] Bhandari SD. Knowledge and practice of postnatal mothers on newborn care at hospital setting. ARC Journal of Nursing and Healthcare 2016;2(1):25-30. 